CLINICAL STUDY

\title{
Response to GH treatment in adult GH deficiency is predicted by gender, age, and IGF1 SDS but not by stimulated GH-peak
}

\author{
Ulla Feldt-Rasmussen ${ }^{1}$, Georg Brabant ${ }^{2}$, Dominique Maiter ${ }^{3}$, Björn Jonsson ${ }^{4}$, Andy Toogood ${ }^{5}$, \\ Maria Koltowska-Haggstrom ${ }^{6}$, Aase Krogh Rasmussen ${ }^{1}$, Michael Buchfelder ${ }^{7}$, Bernhard Saller ${ }^{8}$ \\ and Beverly M K Biller ${ }^{9}$ \\ ${ }^{1}$ Department of Medical Endocrinology. PE 2132, Rigshospitalet, National University Hospital, Copenhagen University, Blegdamsvej 9. \\ DK-2100 Copenhagen, Denmark, ${ }^{2}$ Department of Endocrinology, Christie Hospital, Manchester M2O 4BX, UK, ${ }^{3}$ Department of Endocrinology and \\ Nutrition, University Hospital Saint-Luc, Brussels 1200, Belgium, ${ }^{4}$ Department of Women's and Children's Health, Uppsala University, Uppsala, Sweden, \\ ${ }^{5}$ Department of Endocrinology, University Hospital Birmingham NHS Foundation Trust, Birmingham B15 2TH, UK, ${ }^{6}$ Pfizer, Inc., Sollentuna, Sweden, \\ ${ }^{7}$ Department of Neurosurgery, University of Erlangen Nuernberg, Erlangen 91045, Germany, ${ }^{8}$ Endocrine Care, Pfizer, Inc., Tadworth, UK and \\ ${ }^{9}$ Neuroendocrine Unit, Harvard Medical School, Massachusetts General Hospital, Boston, Massachusetts 02114, USA
}

(Correspondence should be addressed to U Feldt-Rasmussen; Email: ufeldt@rh.dk)

\begin{abstract}
Objective: We studied whether the severity of GH deficiency (GHD) defined as i) GH-peak on stimulation tests (insulin tolerance test (ITT), arginine, and glucagon), ii) number of additional pituitary deficits, or iii) baseline IGF1 SDS could impact the response to GH treatment. We further explored whether iv) IGF1 SDS after 24 months of GH replacement or v) $\triangle$ IGF1 SDS from baseline to 24 months was related to the phenotypic response to $\mathrm{GH}$ treatment.

Design, patients, and measurements: The patient cohort ( $n=1752 ; 50 \%$ women) was obtained from KIMS (Pfizer International Metabolic Database). The patients were divided into three groups of approximately equal size (tertiles) according to the stimulated GH-peak values and baseline IGF1 SDS and were studied at baseline, 12, and 24 months of GH therapy.

Results: Lower baseline IGF1 SDS predicted better response in weight, BMI, total cholesterol, and triglycerides, while IGF1 SDS after 24 months was associated with reduction in waist/hip ratio, total cholesterol, and improved quality of life (QoL). Age-correlated negatively with the response in body weight, BMI, waist, IGF1 SDS, and total and LDL-cholesterol.

Response in weight and BMI was greater in men than in women, whereas women showed greater improvement in QoL than men. Patients with more severe GHD as assessed by lower GH-peaks and more pituitary hormone deficiencies had a greater increase in IGF1 SDS. The increase in IGF1 SDS was associated with a reduction in waist/hip ratio and an increase in weight, BMI, and triglycerides. There was no correlation with other lipids, blood pressure, or glucose.

Conclusion: Our findings indicate that baseline and 24 months, IGF1 and its degree of increase during GH replacement were more important than stimulated peak GH to predict the phenotypic response.
\end{abstract}

European Journal of Endocrinology 168 733-743

\section{Introduction}

Severe GH deficiency (GHD) in adults causes an impairment of quality of life (QoL) $(1,2)$, abnormal body composition $(3,4,5)$, and adverse cardiovascular risk factors (6) that may contribute to the twofold increase in mortality observed in patients with hypopituitarism and not receiving GH replacement therapy $(7,8)$. In children with GHD, the growth velocity serves as a biological marker, which has led to a prediction model for $\mathrm{GH}$ responsiveness in children (9). In adults, however, the features of GHD are not pathognomonic for the condition. Thus, endocrinologists evaluating adults have to rely upon biochemical assessment by a provocative test to identify patients with severe GHD (10). Furthermore, the response to GH replacement is assessed by surrogate markers such as phenotypic features, QoL evaluation, and measurement of insulin-like growth factor 1 (IGF1) (11).

Clinicians prescribing GH to patients with GHD wish to know which patients are most likely to respond to $\mathrm{GH}$ with a measurable improvement, i.e. whether the tests used for the diagnosis of GHD before treatment is started can help predict those who will experience the best clinical benefit from replacement. A few prediction models have been presented $(12,13,14)$, one of which indicated that gender, body height, baseline lean body mass, and serum insulin levels were the major clinical predictors (12). It is well known that the response to $\mathrm{GH}$ treatment is highly individual, and it is therefore of 
clinical interest to determine whether clinical variables measured at the time of GHD diagnosis and during $\mathrm{GH}$ replacement can suggest which patients may ultimately respond better in the long-term.

In our previous studies we showed that even hypopituitary patients with severe GHD, defined as a GH-peak $\leq 3 \mu \mathrm{g} / \mathrm{l}$ at diagnostic testing, demonstrated a relationship between phenotype and the degree of $\mathrm{GH}$ severity $(15,16)$. We now investigate whether the severity of GHD defined as i) GH-peak on stimulation tests (insulin tolerance test (ITT), arginine, and glucagon) $(17,18)$, ii) number of additional pituitary deficits (19), or iii) baseline IGF1 SDS had an impact on the response to GH replacement. We further explored whether iv) the level of IGF1 SDS after 24 months of GH replacement or v) the change $(\Delta)$ of IGF1 SDS from baseline to 24 months was related to the phenotypic response to $\mathrm{GH}$ treatment.

\section{Materials and methods}

KIMS (Pfizer International Metabolic Database), a long-term safety and outcome study of GH replacement therapy in adults, represents a large pharmacoepidemiological survey initiated in 1994 (20). In this database, GH stimulation tests are reported in a standardized fashion along with baseline and followup data on BMI, waist circumference, waist:hip ratio, blood glucose, HbA1c, systolic and diastolic blood pressure, and QoL measured by QoL-Assessment of Growth Hormone Deficiency in Adults score (QoL-AGHDA) (21). Serum samples were analyzed centrally for IGF1 levels and serum lipids (total cholesterol, LDL-cholesterol, HDL-cholesterol, and triglycerides) (22). The GH levels were measured using the available assay at each investigator's institution. We previously analyzed serum GH concentrations in relation to date of entry into the database and demonstrated that there was no time-dependent trend (15). Between 1994 and October 1997, measurements of serum IGF1 were performed at Kabi Pharmacia (Stockholm, Sweden), and thereafter at Sahlgrenska University Hospital (Gothenburg, Sweden), using the following assay methods: until November 2002, RIA after acid/ethanol precipitation of IGF-binding proteins (Nichols Institute Diagnostic, San Juan Capistrano, CA, USA); until September 2006, chemiluminescence immunoassay (Nichols Advantage System); and after September 2006, Immulite 2500 (DPC Siemens, Erlangen, Germany) (23). Intra-assay, inter-assay, and total CV were $<9 \%$ in the concentration range of $125-$ $1046 \mu \mathrm{g} / \mathrm{l}$. The assay detection limit was $13.5 \mu \mathrm{g} / \mathrm{l}$. Age- and gender-specific reference ranges were used to calculate an IGF1 SDS for each patient $(15,24,25)$. Serum total cholesterol, HDL-cholesterol, and triglycerides were measured centrally by standardized methods (26). Serum LDL-cholesterol was calculated according to the Friedewald formula (27). Waist and hip measurements were conducted according to KIMS Guidelines (28) circulated to all participating physicians, and BMI was calculated as body weight $(\mathrm{kg}) /$ height $\left(\mathrm{m}^{2}\right)$.

The patient cohort was obtained from KIMS, which had 13600 adult patients with GHD as of December 2008. Patients were included in this study if they were naïve (no GH treatment before entry), or semi-naïve (not on GH for at least 6 months). Only patients whose diagnosis of GHD was based upon an ITT $(n=1096)$, arginine stimulation test (AST; $n=400$ ), and/or glucagon stimulation test (GST; $n=256$ ) were included. Tests were performed within 1 year before or up to 1 month after entry into KIMS with peak GH $\leq 5.0 \mu \mathrm{g} / \mathrm{l}$. In patients with more than one accepted test, the highest response was used in the analyses.

Other criteria included BMI $<50 \mathrm{~kg} / \mathrm{m}^{2}$, IGF1 SDS $<2$ at baseline, and GH replacement therapy for 24 months with reported visits at baseline, 12, and 24 months. These criteria yielded a cohort of 1752 patients $(881$ women, $50 \%)$. To determine whether treatment response could be predicted by the severity of GHD, the patients were divided before the analysis into three groups with roughly equal numbers of subjects (tertiles). This resulted in three groups with the following ranges of GH-peaks: very severe, $0-0.29 \mu \mathrm{g} / \mathrm{l}$; severe, $0.3-0.8 \mu \mathrm{g} / \mathrm{l}$; and moderate, $0.81-5.0 \mu \mathrm{g} / \mathrm{l}$. The cut-offs were not decided arbitrarily but driven by the data in order to obtain approximately equal group sizes (Table 1). In addition, patients were also grouped according to four prespecified IGF1 SDS ranges $(<-2.0,-2.0$ to $-1.0,-1$ to 0 , and 0 to 2; Table 2).

Comparisons were made between the sub-groups at 12 and 24 months of replacement with $\mathrm{GH}$ for the following available variables: BMI, cholesterol (total, LDL, and HDL), triglycerides, waist circumference, waist/hip ratio, blood glucose, HbA1c, systolic and diastolic blood pressure, and QoL. QoL was determined using the QoL-AGHDA questionnaire (21), where a higher score denotes a poorer QoL and a decrease in score thus indicates improvement.

The responses in IGF1 SDS and GH sensitivity at 12 months were evaluated as predictors for the subsequent phenotypic response at 24 months. GH sensitivity was calculated as the change in IGF1 concentration from baseline to 12 months divided by the administered total amount of $\mathrm{GH}$ in milligrams during the first 12 months of treatment. Furthermore, associations between the variables at 24 months were analyzed using bivariate correlation analyses. Additional analyses were performed to assess for gender difference and evaluate the impact of oral estrogens as well as for use of lipid and glucose-lowering drugs. Finally, data were also analyzed using a cut-off of $3 \mu \mathrm{g} / \mathrm{l}$ by ITT only according to GRS gold standard for diagnosing severe adult GHD (17). 
Table 1 Baseline characteristics of the GH-deficient patients grouped according to severity of GHD by GH-peak tertiles.

\begin{tabular}{|c|c|c|c|c|}
\hline & \multicolumn{4}{|c|}{ Severity of GHD: groups based on GH-peak } \\
\hline & Severe & Moderate & Mild & $P<<^{a}$ \\
\hline Number of patients & 621 & 575 & 556 & \\
\hline GH-peak $(\mu \mathrm{g} / \mathrm{l})$ & $0-0.3$ & $0.3-0.8$ & $0.8-5$ & \\
\hline Gender: females $(\%, n)$ & $44(272)$ & $49(279)$ & $59(330)$ & 0.001 \\
\hline Females using estrogen $(\%, n)$ & 49 (133) & 46 (129) & $38(126)$ & 0.020 \\
\hline Lipid lowering drugs $(\%, n)$ & $27(72)$ & $20(56)$ & $17(56)$ & 0.010 \\
\hline Childhood onset (\%) & 18 & 17 & 14 & NS \\
\hline \multicolumn{5}{|l|}{ Number of additional pituitary deficiencies (\%) } \\
\hline Isolated GHD & 3.5 & 10.6 & 22.3 & \\
\hline 1 & 10.5 & 17.9 & 27.9 & \\
\hline 2 & 15.2 & 19.5 & 21.4 & \\
\hline 3 & 45.5 & 34.7 & 22.1 & \\
\hline 4 & 25.3 & 17.2 & 6.3 & 0.001 \\
\hline \multicolumn{5}{|l|}{ Primary etiology ${ }^{b}(\%)$} \\
\hline Nonfunctioning pituitary adenoma & 31.2 & 28.2 & 27.5 & NS \\
\hline Secreting pituitary adenoma & 23.8 & 25.2 & 27.2 & NS \\
\hline Other sellar tumors & 4.7 & 5.9 & 3.8 & NS \\
\hline Craniopharyngioma & 12.7 & 10.6 & 3.8 & 0.001 \\
\hline Extrasellar tumor & 3.1 & 4.9 & 5.9 & NS \\
\hline Idiopathic GHD & 12.1 & 11.0 & 11.3 & NS \\
\hline Malignancy treatment & 0.3 & 0.9 & 2.3 & 0.004 \\
\hline Traumatic brain injury & 1.8 & 2.3 & 2.2 & NS \\
\hline Other & 10.3 & 11.1 & 16.0 & 0.007 \\
\hline Age at pituitary disease onset (years, mean \pm s.D.) & $36.2 \pm 17.3$ & $36.1 \pm 17.1$ & $36.1 \pm 16.3$ & NS \\
\hline Age at GHD diagnosis (years, mean \pm S.D.) & $43.8 \pm 16.7$ & $42.2 \pm 16.2$ & $41.4 \pm 15.4$ & 0.036 \\
\hline Age at KIMS start (years, mean \pm S.D.) & $46.6 \pm 14.2$ & $44.8 \pm 14.0$ & $43.4 \pm 13.8$ & 0.001 \\
\hline
\end{tabular}

aOver-all, tests were based on one-way ANOVA and Fisher's exact test.

${ }^{b}$ According to the KIMS Classification List (reference: Góth M, Hubina E \& Korbonits M. Aetiology and demography of adult growth hormone deficiency. In Growth Hormone Deficiency in Adults: 10 Years of KIMS, pp 75-82. Eds R Abs \& U Feldt-Rasmussen. Oxford PharmaGenesis, 2004).

\section{Statistical analysis}

Parametric tests were used, such as independent and paired samples $t$-tests and one-way ANOVA, in some cases with post-hoc tests using the least significant difference (LSD) correction. In correlation analyses Pearson's method was used. When nominal data were tested, $\chi^{2}$ tests and Fisher's exact tests were utilized. Additionally, because of very complex relationships and interdependence between clinical characteristics and response to $\mathrm{GH}$, a path analysis (29) was performed.

In the path analysis, indirect effects from exogenous and endogenous variables were measured by path coefficients that are equal to and can be interpreted in the same way as the standardized $\beta$ coefficients $(-1 \leq \beta \leq 1)$ gained in multiple regression analyses. Direct effect from exogenous variables was measured by simple Pearsonian correlation coefficients. The total effect was in each case the sum of direct (direct arrows between boxes in Fig. 1) and indirect effects (e.g. an arrow from the variable in question via another arrow through a second variable to the response). When calculating total effects, the indirect effects of variables, path coefficients, along a path were thus multiplied and added to the direct effect. The absolute size of the total effect mirrored the relative importance of each independent (exogenous or endogenous) variable. In the path analyses, only variables with significant coefficients were used.
In the full model on the dependent variable (change in IGF1 SDS ( $\triangle \mathrm{IGF} 1$ SDS) after 24 months of GH replacement), direct influences were found from age at KIMS entry, gender, and additional pituitary deficits, and the exogenous variables were proposed to influence the intermediary, endogenous variables GH-peak, and IGF1 at baseline, that in turn were supposed to influence GH dose and $\triangle \mathrm{IGF} 1$ SDS.

The standard statistical package (SPSS) for Windows, V20.0 (SPSS, Inc.) was utilized. Data are presented as mean \pm s.D. Statistical significance was considered if $P<0.05$.

\section{Results}

\section{Baseline characteristics according to GH-peak tertiles, IGF1 subgroups, and additional pituitary deficiencies}

At baseline before commencement of GH replacement, there were more females $(59 \%)$ in the group with GH-peak response between 0.8 and $5.0 \mu \mathrm{g} / \mathrm{l}$ compared with the two other groups (44 and $49 \%$ respectively) $(P<0.001$; Table 1$)$. The gender difference was opposite for IGF1 levels; proportionally more women had an IGF1 below -2 SDS (56\%) or between -2 and -1 SDS (50\%) compared with the higher IGF1 subgroups (42 and 43\%) $(P<0.001$; Table 2$)$. 
Table 2 Baseline characteristics of the GH-deficient patients grouped according to prespecified IGF1 SDS values.

\begin{tabular}{|c|c|c|c|c|c|}
\hline & \multicolumn{5}{|c|}{ Severity of GHD: groups based on IGF1 SDS at baseline } \\
\hline & 1 & 2 & 3 & 4 & $P<<^{\mathrm{a}}$ \\
\hline Number of patients & 741 & 457 & 372 & 182 & \\
\hline IGF1 SDS & $<-2$ & -2 to -1 & -1 to 0 & 0 to 2 & \\
\hline Gender: females $(\%, n)$ & $56(417)$ & $50(227)$ & $43(160)$ & $42(77)$ & 0.001 \\
\hline Childhood onset (\%) & 32.1 & 7.4 & 4.6 & 2.7 & 0.001 \\
\hline \multicolumn{6}{|l|}{ Number of additional pituitary deficiencies (\%) } \\
\hline Isolated GHD & 10.0 & 10.3 & 15.3 & 15.9 & \\
\hline 1 & 13.7 & 19.9 & 22.3 & 26.4 & \\
\hline 2 & 16.0 & 21.7 & 21.2 & 15.9 & \\
\hline 3 & 39.6 & 31.9 & 30.1 & 29.1 & \\
\hline 4 & 20.7 & 16.2 & 11.0 & 12.6 & 0.001 \\
\hline \multicolumn{6}{|l|}{ Primary etiology ${ }^{\mathrm{b}}(\%)$} \\
\hline Nonfunctioning pituitary adenoma & 18.5 & 38.5 & 36.6 & 33.0 & 0.001 \\
\hline Secreting pituitary adenoma & 21.3 & 25.6 & 28.0 & 35.7 & 0.001 \\
\hline Other sellar tumors & 6.2 & 4.4 & 2.2 & 5.5 & 0.025 \\
\hline Craniopharyngioma & 11.5 & 7.0 & 8.6 & 6.6 & 0.031 \\
\hline Extrasellar tumor & 5.7 & 4.4 & 3.2 & 3.3 & NS \\
\hline Idiopathic GHD & 19.7 & 5.0 & 5.9 & 5.5 & 0.001 \\
\hline Malignancy treatment & 0.7 & 1.5 & 1.9 & 0.5 & NS \\
\hline Traumatic brain injury & 2.2 & 1.8 & 2.4 & 1.6 & NS \\
\hline Other & 14.3 & 11.8 & 11.3 & 8.2 & NS \\
\hline Age at pituitary disease onset (years, mean \pm s.D.) & $28.3 \pm 16.7$ & $39.9 \pm 15.4$ & $42.6 \pm 14$ & $44.8 \pm 13.4$ & 0.001 \\
\hline Age at GHD diagnosis (years, mean \pm s.D.) & $35.8 \pm 17.4$ & $46 \pm 13.9$ & $47.8 \pm 12.8$ & $50.2 \pm 11.8$ & 0.001 \\
\hline Age at KIMS start (years, mean \pm s.D.) & $39.8 \pm 14.3$ & $47.6 \pm 13.4$ & $49 \pm 12.2$ & $51.5 \pm 11.2$ & 0.001 \\
\hline
\end{tabular}

${ }^{a} O v e r-a l l$, tests were based on one-way ANOVA and $\chi^{2}$. $P$ values indicate 'over-all' difference.

${ }^{\mathrm{b}}$ According to the KIMS Classification List (reference: Góth M, Hubina E \& Korbonits M. Aetiology and demography of adult growth hormone deficiency. In Growth Hormone Deficiency in Adults: 10 Years of KIMS, pp 75-82. Eds R Abs \& U Feldt-Rasmussen. Oxford PharmaGenesis, 2004).

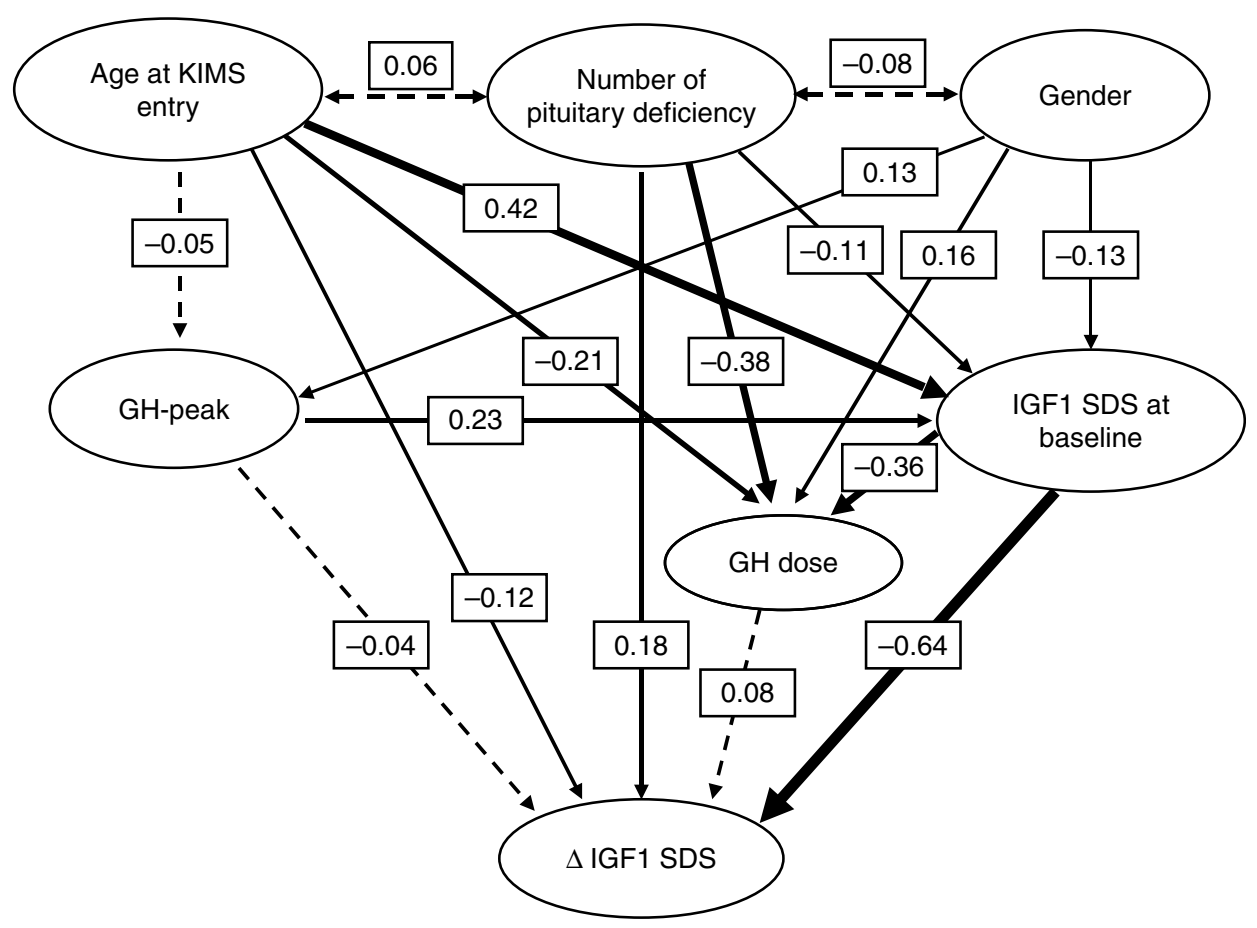

Figure 1 Path analysis of the complex interrelations between GH dose at 24 months. Baseline variables and change in IGF1 SDS from baseline to 24 months. Numbers in the figure represent path coefficients $(\beta)$. The total effect from the variables in the model was accounted for by IGF1 SDS at baseline (-0.67), age $(-0.39)$, additional pituitary hormone deficiencies $(0.29)$, GH-peak at stimulation test $(-0.19)$, $\mathrm{GH}$ dose at 24 months (0.08), and gender (0.05). 


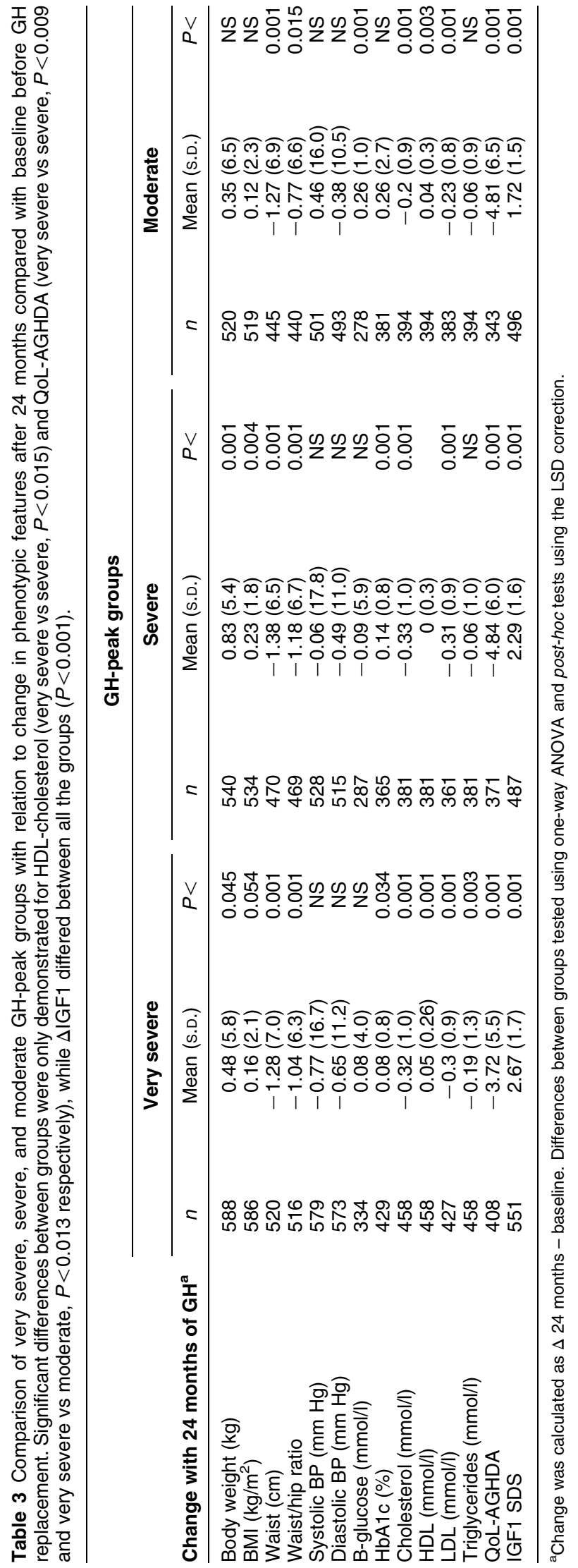

Women were more likely than men to have no, one, or two other pituitary deficiencies $(53,58$, and $55 \%$ respectively), compared with three or four additional deficiencies (43 and 49\%) $(P<0.001$; data not shown). Among the women, $44 \%(n=388)$ used estrogens (most of them orally), with a lower proportion among the patients with the highest GH-peak (Table 1). A number of patients $(132,0.5 \%)$ used glucoselowering drugs, distributed evenly among the subgroups. However, among the $370(17 \%)$ patients taking lipid-lowering drugs, a lower proportion was found in the group with the highest GH-peak (Table 1). There were significantly more craniopharyngiomas in the groups with the lowest GH-peak and IGF1 SDS and in the group with most additional deficiencies (Tables 1 and 2). Idiopathic GHD was more often seen in isolated GHD, and more often had lower IGF1 SDS $(P<0.001)$ but similar GH-peak. The other diagnoses were largely similar among the groups. Age at diagnosis of GHD and at KIMS start was higher in the very severe group, in the 0-2 SDS IGF1 group, and in the group with fewer additional pituitary hormone deficiencies. Childhood onset GHD was more prevalent in isolated GHD and in the subgroup with lower IGF1 SDS but was similarly distributed across the GH-peak groups (Tables 1 and 2).

\section{GH-peak and phenotypic response to GH replacement}

Comparisons of the GH-peak groups (very severe, severe, and moderate GHD) in relation to change in phenotypic features after 24 months of GH replacement are shown in Table 3. Compared with baseline, significant differences between the three groups were demonstrated after 2 years of treatment for HDL-cholesterol, which increased slightly more on replacement $(0.05 \mathrm{mmol} / \mathrm{l})$ in the very severe group compared with the severe group $(P<0.05)$, which in turn showed no change. Body weight and waist circumference decreased more in the very severe group at 12 months (data not shown), but this difference between groups was not sustained at 24 months. QoL-AGHDA scores at both 12 (data not shown) and 24 months (Table 3) improved less in the very severe group $(-3.7 \pm 5.5)$ compared with both the severe $(-4.8 \pm 6.0, P<0.009)$ and the moderate group $(-4.8 \pm 6.5, P=0.013)$. The change in IGF1 SDS at both 12 and 24 months was more pronounced in the very severe GH-peak group and differed between all three groups, with a mean increase of $2.7 \pm 1.7$ in the very severe, $2.3 \pm 1.6$ in the severe, and $1.7 \pm 1.5$ in the moderate GH-peak group respectively $(P<0.001)$. The lower the GH-peak, the more pronounced was the increase in IGF1 SDS, but the less pronounced the improvement in QoL. These associations were seen in the background of the very severe group having more men than the other two groups, and patients with craniopharyngioma and nonfunctioning pituitary adenoma, while the mean age at diagnosis of the pituitary disease as well as at start in KIMS was higher (Table 1). 


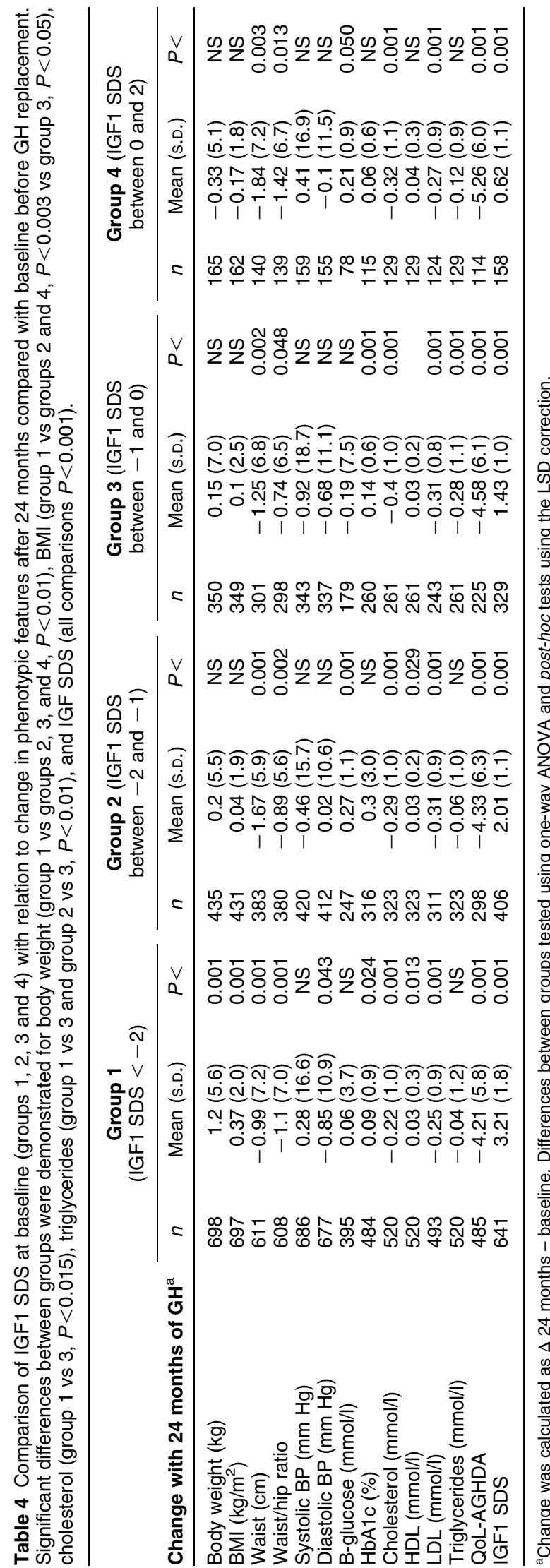

Thus, a low GH-peak predicted a good IGF1 response but with a poorer QoL outcome and no significant differences in any of the other phenotypic features. Reanalyses using a cut-off of $3 \mu \mathrm{g} / \mathrm{l}$ showed similar results to the analyses mentioned above (data not shown).

\section{IGF1 SDS at baseline and phenotypic response to GH replacement}

Except for a minor relationship between blood pressure, $\mathrm{HbAlc}$, lipids, and additional pituitary hormone deficiencies at 24 months, only $\triangle$ IGF1 SDS at 12 and 24 months had a consistent association with IGF1 SDS at baseline (data not shown). Table 4 shows the comparison between the four IGF1 subgroups at baseline (subgroup $1=$ the lowest IGF1 SDS) regarding changes in phenotypic features after 24 months. Significantly larger increases were demonstrated in the lowest IGF1 SDS subgroup for body weight (group 1 vs groups 2,3 , and $4, P<0.001$ ) and BMI (group 1 vs groups 2 and $4, P<0.006$ ), while larger decrements were seen in the higher IGF1 SDS subgroup for total cholesterol (group 1 vs $3, P<0.014$ ) and triglycerides (group 1 vs 3 and group 2 vs $3, P<0.01$ ). Lower IGF1 SDS at baseline was associated with a more pronounced increase in weight $(r=-0.09, P<0.0001)$, BMI $(r=-0.08, P<0.01)$, total cholesterol $(r=-0.08$, $P<0.01)$, and triglycerides $(r=-0.07, P<0.05)$. The $\Delta$ IGF1 SDS differed among all groups, with a larger change seen in patients with lower IGF1 SDS at baseline (all comparisons $P<0.001$ ). In a subgroup analysis, women using estrogens $(n=388,44 \%)$ had lower IGF1 levels at baseline and responded with a higher $\triangle \mathrm{IGF} 1$. Most of these differences between the groups had also been seen after 12 months (data not shown) and were thus sustained through 24 months of GH replacement. These associations were observed with the background of the lowest IGF1 group $(<-2$ SDS) containing a higher proportion of patients who were female, had childhood onset pituitary disease, were younger at pituitary diagnosis and KIMS start, and more frequently had craniopharyngiomas, additional pituitary insufficiencies, and idiopathic GHD (Table 2).

\section{Number of additional pituitary insufficiencies at baseline and phenotypic response to GH replacement}

There were statistically significant differences between groups characterized by the number of additional pituitary hormone deficiencies, in terms of gender, age, etiology, onset of disease, age at onset of the pituitary disease, and entrance into KIMS (data not shown). Waist circumference showed a more marked decrease in the group without additional deficiencies compared with the others $(P<0.04)$, and increasing number of deficiencies resulted in a larger increment of IGF1 SDS. No other associations were identified. 


\section{Other baseline features influencing the phenotypic response to GH replacement}

Patients with a high body weight at baseline decreased their weight more than leaner subjects $(r=-0.10, P<0.0001)$ and age was also negatively correlated to the response to $\mathrm{GH}$ in weight $(r=-0.15, P<0.0001)$, BMI $(r=-0.12$, $P<0.0001)$, waist circumference $(r=-0.06, P<0.05)$, total cholesterol $(r=-0.08, P<0.01)$, and LDL-cholesterol $(r=-0.09, P<0.01)$ (data not shown).

Compared with men, women decreased weight $(P<0.05)$ and BMI $(P<0.05)$ to a lesser degree but increased QoL more $(P<0.01)$. The GH-peak and number of additional hormone deficiencies predicted only the $\Delta$ IGF1 SDS $(r=-0.23$ and 0.18 respectively $P<0.0001$; data not shown).

\section{Prediction of GH response at 24 months by first year response to GH}

The GH sensitivity in the whole cohort of patients demonstrated a bell-shaped distribution. GH sensitivity predicted the phenotypic response from 12 to 24 months in diastolic blood pressure $(r=-0.09, P<0.001)$, total cholesterol $(r=-0.07, P<0.05)$, and IGF1 SDS $(r=-0.31, P<0.0001)$. IGF1 SDS at 12 months predicted the response in waist circumference $(r=0.07, P<0.05)$ and total cholesterol $(r=-0.06$, $P<0.05)$, while change in IGF1 SDS within the first year predicted the change of BMI $(r=0.06, P<0.05)$, blood glucose $(r=-0.10, P<0.01)$, and the change of IGF1 SDS $(r=-0.31, P<0.0001)$. The negative association between peak $\mathrm{GH}$ and baseline and $\Delta \mathrm{IGF} 1$, respectively, was slightly attenuated by controlling for estrogen use, but still highly significant $(P<0.00001$; data not shown).

\section{Association between outcomes of 24 months' GH replacement}

$\triangle$ IGF1 SDS correlated positively with the change in weight $(r=0.13, P<0.0001$; Fig. 2, Table 5), BMI $(r=0.11, P<0.0001)$, and triglycerides $(r=0.06$, $P<0.05)$, and negatively with waist/hip ratio $(r=-0.07, P<0.05)$. In other words, an increase in IGF1 SDS after 24 months was associated with a reduction in waist/hip ratio. IGF1 SDS at 24 months was negatively correlated with a change in waist/hip ratio $(r=-0.06, P<0.05)$, change in QoL-AGHDA score $(r=-0.09, P<0.01$; in men NS; in women: $r=-0.17, P<0.001)$, and change in total cholesterol ( $r=-0.06, P<0.05)$, the latter of which disappeared when controlling for use of lipid lowering drugs.

\section{Path analysis of the change of IGF1 SDS from baseline to 24 months, $I$ IGF1 SDS}

Path analysis confirmed the complexity of interrelations between the variables involved in the change of IGF1
SDS in response to GH (Fig. 1, Table 5). IGF1 SDS at baseline had the most important influence on $\Delta$ IGF1 SDS $(\beta=-0.64)$ and this influence was further strengthened to -0.67 , through the indirect effect via
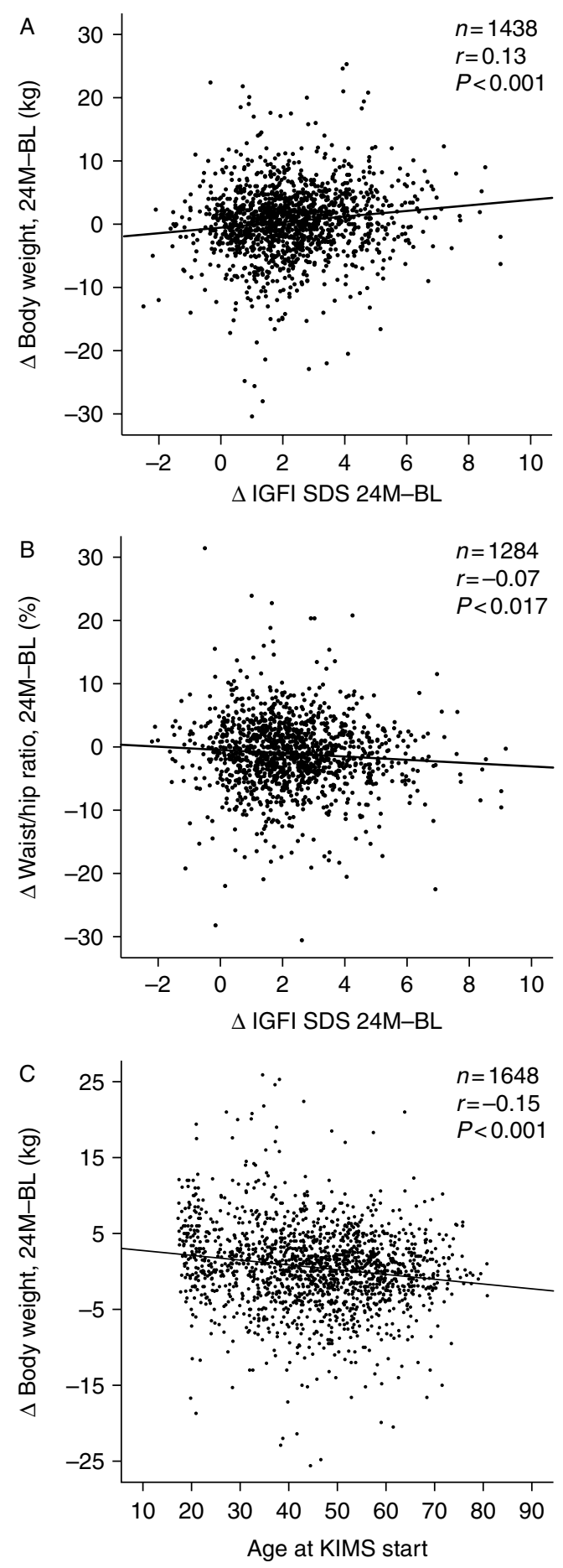

Figure 2 Scattergrams showing change $(\Delta)$ in $(A)$ body weight and (B) waist hip ratio vs change in IGF1 SDS after 24 months of GH replacement therapy of adult patients with GHD and change (C) in body weight vs age at KIMS entry. 
Table 5 Significant and borderline significant correlation coefficients between change in a number of variables between baseline (BL) and 24 months (24M) of GH replacement and stimulated GH-peak, additional hormone deficiencies, IGF1 SDS at baseline, and IGF1 SDS at 24 months. IGF1 SDS, GH dose at 24 months, and GH sensitivity at 24 months. The correlation between IGF1 at 24 months and cholesterol disappeared after controlling for use of lipid lowering drugs, while all other correlations remained when controlling for this and for glucose-lowering drugs.

\begin{tabular}{|c|c|c|c|c|c|c|c|}
\hline Change 24M - BL & GH-peak & $\begin{array}{c}\text { Additional } \\
\text { pituitary } \\
\text { hormone } \\
\text { deficits }\end{array}$ & $\begin{array}{l}\text { IGF1 at } \\
\text { baseline }\end{array}$ & $\begin{array}{l}\text { IGF1 at } 24 \\
\text { months }\end{array}$ & $\Delta \mathrm{IGF1}$ & $\begin{array}{l}\text { Dose at } 24 \\
\text { months }\end{array}$ & GH sensitivity \\
\hline \multicolumn{8}{|l|}{ Body weight (kg) } \\
\hline $\begin{array}{l}r \\
P<\end{array}$ & & & $\begin{array}{r}-0.091 \\
\mathbf{0 . 0 0 1}\end{array}$ & & $\begin{array}{l}0.129 \\
\mathbf{0 . 0 0 1}\end{array}$ & & $\begin{array}{l}0.08 \\
\mathbf{0 . 0 0 2}\end{array}$ \\
\hline \multicolumn{8}{|l|}{ BMI $\left(\mathrm{kg} / \mathrm{m}^{2}\right)$} \\
\hline $\begin{array}{l}r \\
P<\end{array}$ & & & $\begin{array}{r}-0.075 \\
\mathbf{0 . 0 0 2}\end{array}$ & & $\begin{array}{l}0.113 \\
0.001\end{array}$ & & $\begin{array}{l}0.084 \\
0.001\end{array}$ \\
\hline $\begin{array}{l}\text { Waist }(\mathrm{cm}) \\
r \\
P<\end{array}$ & & & & $\begin{array}{r}-0.053 \\
0.057\end{array}$ & & & \\
\hline \multicolumn{8}{|l|}{ Waist/Hip ratio } \\
\hline $\begin{array}{l}r \\
P<\end{array}$ & & & & $\begin{array}{r}-0.061 \\
\mathbf{0 . 0 2 8}\end{array}$ & $\begin{array}{r}-0.067 \\
\mathbf{0 . 0 1 7}\end{array}$ & & \\
\hline \multicolumn{8}{|l|}{$r$} \\
\hline \multicolumn{8}{|l|}{ Diastolic BP (mm Hg) } \\
\hline$r$ & & & 0.043 & & & & \\
\hline$P<$ & & & 0.087 & & & & \\
\hline \multicolumn{8}{|l|}{ B-glucose (mmol/l) } \\
\hline $\begin{array}{l}r \\
P<\end{array}$ & & & & & & & $\begin{array}{l}0.064 \\
0.068\end{array}$ \\
\hline \multicolumn{8}{|l|}{$\mathrm{HbA1c}(\%)$} \\
\hline $\begin{array}{l}r \\
P<\end{array}$ & $\begin{array}{l}0.052 \\
0.074\end{array}$ & & & & & & \\
\hline \multicolumn{8}{|l|}{ Cholesterol (mmol/l) } \\
\hline $\begin{array}{l}r \\
P<\end{array}$ & & & $\begin{array}{r}-0.081 \\
\mathbf{0 . 0 0 5}\end{array}$ & $\begin{array}{r}-0.061 \\
\mathbf{0 . 0 3 3}\end{array}$ & & & \\
\hline \multicolumn{8}{|l|}{$\mathrm{HDL}(\mathrm{mmol} / \mathrm{l})$} \\
\hline $\begin{array}{l}r \\
P<\end{array}$ & & & & $\begin{array}{c}-0.05 \\
0.078\end{array}$ & & & \\
\hline \multicolumn{8}{|l|}{$\begin{array}{l}r \\
P<\end{array}$} \\
\hline \multicolumn{8}{|l|}{ Triglycerides $(\mathrm{mmol} / \mathrm{l})$} \\
\hline $\begin{array}{l}r \\
P<\end{array}$ & & & $\begin{array}{r}-0.069 \\
\mathbf{0 . 0 1 5}\end{array}$ & & $\begin{array}{l}0.059 \\
\mathbf{0 . 0 3 8}\end{array}$ & & \\
\hline \multicolumn{8}{|l|}{ QoL-AGHDA } \\
\hline $\begin{array}{l}r \\
P<\end{array}$ & $\begin{array}{r}-0.054 \\
0.072\end{array}$ & & $\begin{array}{r}-0.057 \\
0.058\end{array}$ & $\begin{array}{r}-0.094 \\
\mathbf{0 . 0 0 3}\end{array}$ & & & \\
\hline
\end{tabular}

GH dose. Thus, patients with a low-basal IGF1 SDS had a greater $\triangle \mathrm{IGF} 1$ SDS at 24 months than patients with higher IGF1 SDS levels.

Age at KIMS start had a direct influence on $\triangle \mathrm{IGF} 1$ SDS $(r=-0.12)$. This effect was strengthened by the paths via IGF1 SDS at baseline and GH dose and weakened somewhat by the path via the number of additional deficits $(r=0.06)$. The total effect of age was -0.41 , i.e. with increasing age, IGF1 SDS changed less under GH replacement therapy.

The number of pituitary hormone deficits in addition to GHD had a direct effect on $\triangle \mathrm{IGF} 1 \mathrm{SDS}(r=0.18)$. The total effect was 0.32 , reached through the paths via all the intermediary predictors.

Gender by itself did not have a significant correlation with $\triangle \mathrm{IGF} 1$ SDS. The total influence of gender was thus weak (0.05) and reached through paths via all intermediary predictors but weakened by the reciprocal correlation with the number of additional pituitary deficits.

The GH-peak had an indirect path to $\triangle$ IGF1 SDS with a low $\beta$ coefficient $(-0.04)$, but the total effect was enforced by another indirect effect via basal IGF1 SDS and therefore amounted to -0.19 .

GH dose at 24 months was at the last position in the chain of predictors, and thus had only one path to $\Delta \mathrm{IGF} 1$ SDS with a weak $\beta$ coefficient of 0.08 (Fig. 1).

\section{Discussion}

The response to $\mathrm{GH}$ replacement in adults is less predictable than in children and includes many 
variables such as changes in body composition, QoL, and blood lipids $(30,31)$, and many confounders have to be taken into account $(32,33)$. Prediction models in children with short stature incorporated data from a very large number of patients in the calculations $(9,34,35)$. In contrast, prediction of GH response has been described in only a limited number of adults with $\operatorname{GHD}(12,13,14)$, and we therefore explored predictors of response using the large KIMS database (20).

The original and follow-up consensus statements of the Growth Hormone Research Society identified ITT as a gold standard simulation test for diagnosing severe GHD (peak GH $<3 \mu \mathrm{g} / \mathrm{l}$ ) in adults $(17,18)$. Toogood et al. (19) demonstrated that the severity of hypopituitarism as indicated by the number of anterior pituitary hormone deficits was associated with the GH response to ITT. This observation was substantiated in our previous studies of larger patient cohorts with severe GHD based on peak GH of $<3 \mu \mathrm{g} / \mathrm{l}$ during ITT, AST, or GST stimulation tests $(15,16)$. In our selection of the patient cohort for the current study, we included those who had a GHD diagnosis confirmed by any of the three tests, allowing a cut-off $<5 \mu \mathrm{g} / \mathrm{l}$ in order not to exclude young adult patients, whose cut-off levels are considered to be higher than in older adults (36). The cut-off of $<5 \mu \mathrm{g} / \mathrm{l}$ has furthermore been demonstrated to provide a more optimal sensitivity and precision in receiver operating curves (ROC) curves distinguishing hypopituitary patients from controls (37). Nevertheless, we performed analyses using the classical cut-off of $<3 \mu \mathrm{g} / \mathrm{l}$ which confirmed our results.

In a prior study on patients with severe GHD, the age at which the patient was tested did not affect the performance of the ITT, AST, and GST (16). This suggested that the impact of pituitary disease overrode the subtle changes that occur in the regulation of GH secretion with aging and need not be taken into account when diagnosing GHD in this clinical scenario $(16,38)$. On the other hand, in the current study on hypopituitary patients with GHD, older age negatively predicted the response to GH in weight, BMI, waist circumference, and total and LDL-cholesterol, in keeping with a previous description of $\mathrm{GH}$ replacement in the elderly (39), while others have identified elderly GHD patients as a GH-sensitive group $(40,41)$.

Obesity has consistently been shown to inhibit spontaneous GH secretion and all dynamic function tests that have been studied - the greater the BMI, the less $\mathrm{GH}$ produced $(16,33,37,42)$. Concerns have therefore been raised that obesity may compromise a reliable diagnosis of $\mathrm{GHD}$ because the $\mathrm{GH}$ response to stimulation tests will be attenuated. It is also possible that the benefit of GH replacement might be hampered by obesity. The current study was therefore reassuring that patients who were obese at baseline decreased their weight more than patients with lower body weight. Conversely, body weight and BMI both increased with increasing increment of IGF1 SDS. However, waist circumference and waist/hip ratio decreased with increasing increment of IGF1 SDS, suggesting that GH replacement therapy increased muscle mass rather than fat mass. Another possibility may be a weight gain due to water and sodium retention through renal effects of GH (43). A more precise evaluation of body composition was, however, unavailable in KIMS to test this hypothesis.

Serum IGF1 has a limited role in the diagnosis of GHD in adults (10), although the levels are highly influenced by $\mathrm{GH}$ status and there are correlations between the two (15). In our current study, IGF1 SDS was a strong predictor of the response to GH replacement, in agreement with some previous reports (44), but in disagreement with others $(12,13,14)$. We also found that women using estrogens had lower IGF1 levels at baseline but responded better in terms of $\triangle \mathrm{IGF} 1$. A recent study developed accurate mathematical models to predict GH responsiveness in GHD adults and found gender, body height, baseline lean body mass, and serum insulin levels as the major clinical predictors (12). We were not able to test this model, since measurements of lean body mass and insulin were not available in the KIMS database.

There are a number of limitations to our study. Unlike IGF1, GH was measured in each individual laboratory, which was a possible confounder of the results of GH-peaks. GH measurements are generally not very well standardized between methods and laboratories (45), and the period for entrance of patients into the KIMS database spanned more than 15 years. However, we have previously detected no variation in the GH-peaks over time (15). Furthermore, the size of the study should theoretically eliminate or at least diminish the influence from confounders and method variation, but it cannot be excluded that the results were partly affected by differences in GH measurements. Although central IGF1 measurements is one of the strengths of our study, it is worth mentioning that there were a number of changes in the assay methods used, which may also have influenced the results. Finally, adjustment for changes in other hormone replacements was not performed because of variability in the accuracy of concomitant medication reporting.

In summary, the extent of hypopituitarism indicated by the GH stimulation test peak and the number of additional hormone deficiencies did not have an independent impact on the response to GH but predicted only the IGF1 SDS response. IGF1 at baseline predicted the GH treatment response in weight, BMI, cholesterol, and triglycerides; age predicted the response in body weight, BMI, waist, and total and LDL-cholesterol, while gender predicted the responsiveness in weight, BMI, and QoL-AGHDA. In addition, the IGF1 response to $\mathrm{GH}$ treatment from baseline to 24 months, as well as the IGF1 SDS with 24 months of replacement, was associated with a positive treatment effect on weight, BMI, waist/hip ratio, and triglycerides, but not 
on other lipids, blood pressure, or blood glucose, and with reduction in waist/hip, total cholesterol, and QoL-AGHDA respectively.

In conclusion, our findings have indicated that IGF1 at baseline and at 24 months, as well as its change during treatment, played a more important role than peak $\mathrm{GH}$ to stimulation testing in predicting the phenotypic response to GH replacement. However, the clinical implications of these observations remain to be proven in future studies.

\section{Declaration of interest}

G Brabant, B M K Biller, M Buchfelder, U Feldt-Rasmussen, D Maiter, A Toogood, and B Jonsson received consulting fees from Pfizer, Inc. U Feldt-Rasmussen received research funding from Novo Nordisk. B M K Biller received consulting fees from Novo Nordisk and research funding from Novo Nordisk, Pfizer, and Merck Serono. M KoltowskaHaggstrom is an employee of Pfizer, Inc. (Sweden), and B Saller is an employee of Pfizer, Inc. (UK).

\section{Funding}

Pfizer sponsored the KIMS database. U Feldt-Rasmussen received a research grant from Arvid Nilsson's Fund. Salary for her research time is paid by this fund. No authors were paid for their contributions to this manuscript.

\section{References}

1 Burman P, Broman JE, Hetta J, Wiklund I, Erfurth EM, Hagg E \& Karlsson FA. Quality of life in adults with growth hormone $(\mathrm{GH})$ deficiency: response to treatment with recombinant human GH in a placebo-controlled 21-month trial. Journal of Clinical Endocrinology and Metabolism 199580 3585-3590. (doi:10.1210/jc. 80.12.3585)

2 McGauley GA, Cuneo RC, Salomon F \& Sonksen PH. Psychological well-being before and after growth hormone treatment in adults with growth hormone deficiency. Hormone Research 199033 (Suppl 4) 52-54. (doi:10.1159/000181584)

3 Beshyah SA, Freemantle C, Thomas E, Rutherford O, Page B, Murphy M \& Johnston DG. Abnormal body composition and reduced bone mass in growth hormone deficient hypopituitary adults. Clinical Endocrinology 199542 179-189. (doi:10.1111/j. 1365-2265.1995.tb01860.x)

4 Lonn L, Kvist H, Grangård U, Bengtsson BA \& Sjöström L. CT-determined body composition changes with recombinant human growth hormone treatment to adults with growth hormone deficiency. Basic Life Sciences 199360 229-231.

5 Holmes SJ, Economou G, Whitehouse RW, Adams JE \& Shalet SM. Reduced bone mineral density in patients with adult onset growth hormone deficiency. Journal of Clinical Endocrinology and Metabolism 199478 669-674. (doi:10.1210/jc.78.3.669)

6 Toogood AA. Cardiovascular risk and mortality in patients with growth hormone deficiency. In Growth Hormone Deficiency in Adults: 10 Years of KIMS, edn 1st edn, pp 63-74. Eds R Abs \& U Feldt-Rasmussen, Oxford: Oxford Pharmagenesis, 1994.

7 Tomlinson JW, Holden N, Hills RK, Wheatley K, Clayton RN, Bates AS, Sheppard MC \& Stewart PM. Association between premature mortality and hypopituitarism. West Midlands Prospective Hypopituitary Study Group. Lancet 2001357 425-431. (doi:10.1016/S0140-6736(00)04006-X)

8 Rosen T \& Bengtsson B. Premature mortality due to cardiovascular disease in hypopituitarism. Lancet $1990 \mathbf{3 3 6}$ 285-288. (doi:10.1016/0140-6736(90)91812-0)
9 Ranke MB, Lindberg A, Chatelain P, Wilton P, Cutfield W, Albertsson-Wikland K \& Price DA. Derivation and validation of a mathematical model for predicting the response to exogenous recombinant human growth hormone (GH) in prepubertal children with idiopathic GH deficiency. KIGS International Board. Kabi Pharmacia International Growth Study. Journal of Clinical Endocrinology and Metabolism 199984 1174-1183. (doi:10.1210/jc.84.4.1174)

10 Shalet SM, Toogood A, Rahim A \& Brennan BM. The diagnosis of growth hormone deficiency in children and adults. Endocrine Reviews 199819 203-223. (doi:10.1210/er.19.2.203)

11 Monson JP. Long-term experience with GH replacement therapy: efficacy and safety. European Journal of Endocrinology $2003 \mathbf{1 4 8}$ (Suppl 2) S9-S14. (doi:10.1530/eje.0.148S009)

12 Barbosa EJ, Koranyi J, Filipsson H, Bengtsson BA, Boguszewski CL \& Johannsson G. Models to predict changes in serum IGF1 and body composition in response to GH replacement therapy in GH-deficient adults. European Journal of Endocrinology 2010162 869-878. (doi:10.1530/EJE-09-0973)

13 De Vries WR, Koppeschaar HP, Bol E, Roelen CA, Donker GH, Doerga ME, Osman-Dualeh M \& Snel YE. Intersubject responsiveness of high-affinity growth hormone (GH)-binding protein (GHBP) to long-term GH replacement therapy. Journal of Endocrinological Investigation 200023 449-456.

14 Johannsson G. Gender difference in growth hormone response in adults. Journal of Endocrinological Investigation 199922 58-60.

15 Brabant G, Krogh Rasmussen A, Biller BM, Buchfelder M, Feldt-Rasmussen U, Forssmann K, Jonsson B, KoltowskaHaggstrom M, Maiter D, Saller B et al. Clinical implications of residual growth hormone $(\mathrm{GH})$ response to provocative testing in adults with severe GH deficiency. Journal of Clinical Endocrinology and Metabolism 200792 2604-2609. (doi:10.1210/jc.2007-0153)

16 Toogood A, Brabant G, Maiter D, Jonsson B, Feldt-Rasmussen U, Koltowska-Haggstrom M, Rasmussen AK, Buchfelder M, Saller B \& Biller BM. Patients diagnosed with severe adult GH deficiency using the insulin tolerance test, arginine or glucagone stimulation tests share similar clinical features. Endocrine Practice $201181-26$.

17 Growth Hormone Research Society. Consensus guidelines for the diagnosis and treatment of adults with growth hormone deficiency: summary statement of the Growth Hormone Research Society workshop on adult growth hormone deficiency. Journal of Clinical Endocrinology and Metabolism 199883 379381. (doi:10.1210/jc.83.2.379)

18 Ho KK. Consensus guidelines for the diagnosis and treatment of adults with GH deficiency. II: a statement of the GH Research Society in association with the European Society for Pediatric Endocrinology, Lawson Wilkins Society, European Society of Endocrinology, Japan Endocrine Society, and Endocrine Society of Australia. European Journal of Endocrinology 2007157 695700. (doi:10.1530/EJE-07-0631)

19 Toogood AA, Beardwell CG \& Shalet SM. The severity of growth hormone deficiency in adults with pituitary disease is related to the degree of hypopituitarism. Clinical Endocrinology $1994 \mathbf{4 1}$ 511-516. (doi:10.1111/j.1365-2265.1994.tb02583.x)

20 Gutierrez LP, Koltowska-Haggstrom M, Jonsson PJ, Mattsson AF, Svensson D, Westberg B \& Luger A. Registries as a tool in evidencebased medicine: example of KIMS (Pfizer International Metabolic Database). Pharmacoepidemiology and Drug Safety 2008 17 90-102. (doi:10.1002/pds.1510)

21 McKenna SP, Doward LC, Alonso J, Kohlmann T, Niero M, Prieto L \& Wiren L. The QoL-AGHDA: an instrument for the assessment of quality of life in adults with growth hormone deficiency. Quality of Life Research $1999 \mathbf{8}$ 373-383. (doi:10.1023/ A:1008987922774)

22 Abs R, Bengtsson BA, Hernberg-Stahl E, Monson JP, Tauber JP, Wilton P \& Wuster C. GH replacement in 1034 growth hormone deficient hypopituitary adults: demographic and clinical characteristics, dosing and safety. Clinical Endocrinology $1999 \mathbf{5 0}$ 703-713. (doi:10.1046/j.1365-2265.1999.00695.x) 
23 Underwood LE \& Murphy MG. Radioimmunoassay of the somatomedins/insulin-like growth factors. In Radioimmunoassay in Basic and Clinical Pharmacology, pp 561-574. Eds C Patrano \& BA Peskar, Berlin: Springer-Verlag, 1987 (198724).

24 Brabant G, von zur Muhlen A, Wuster C, Ranke MB, Kratzsch J, Kiess W, Ketelslegers JM, Wilhelmsen L, Hulthen L, Saller B et al. Serum insulin-like growth factor I reference values for an automated chemiluminescence immunoassay system: results from a multicenter study. Hormone Research 200360 53-60. (doi:10.1159/000071871)

25 Gaillard RC, Mattsson AF, Åkerblad A-C, Bengtsson B-A, Cara J, Feldt-Rasmussen U, Koltowska-Häggström M, Monson JP, Saller B, Wilton $\mathrm{P}$ et al. Overall and cause-specific mortality in growth hormone-deficient adults on growth hormone replacement. European Journal of Endocrinology $2012 \mathbf{1 6 6} 1069-1077$. (doi:10.1530/EJE-11-1028)

26 Feldt-Rasmussen U, Abs R, Bengtsson BA, Bennmarker $\mathrm{H}$, Bramnert M, Hernberg-Stahl E, Monson JP, Westberg B, Wilton $\mathrm{P} \&$ Wuster C. Growth hormone deficiency and replacement in hypopituitary patients previously treated for acromegaly or Cushing's disease. European Journal of Endocrinology 2002146 67-74. (doi:10.1530/eje.0.1460067)

27 Friedewald WT, Levy RI \& Fredrickson DS. Estimation of the concentration of low-density lipoprotein cholesterol in plasma, without use of the preparative ultracentrifuge. Clinical Chemistry 197218 499-502.

28 Bengtsson BA, Abs R, Bennmarker H, Monson JP, FeldtRasmussen U, Hernberg-Stahl E, Westberg B, Wilton P \& Wuster $\mathrm{C}$. The effects of treatment and the individual responsiveness to growth hormone $(\mathrm{GH})$ replacement therapy in 665 GH-deficient adults. KIMS Study Group and the KIMS International Board. Journal of Clinical Endocrinology and Metabolism 199984 3929-3935. (doi:10.1210/jc.84.11.3929)

29 Alwin DF \& Hauser RM. The decomposition of effects in path analysis. American Sociological Review $1975 \mathbf{4 0} 37-47$. (doi:10.2307/2094445)

30 Jorgensen JOL, Pedersen SA, Thuesen L, Jorgensen J, Ingemann-Hansen T, Skakkebaek NE \& Christiansen JS. Beneficial effects of growth hormone treatment in GH-deficient adults. Lancet 19891 1221-1225. (doi:10.1016/S0140-6736 (89)92328-3)

31 Salomon F, Cuneo RC, Hesp R \& Sonksen PH. The effects of treatment with recombinant human growth hormone on body composition and metabolism in adults with growth hormone deficiency. New England Journal of Medicine 1989321 1797-1803. (doi:10.1056/NEJM198912283212605)

32 Iranmanesh A, Lizarralde G \& Veldhuis JD. Age and relative obesity are specific negative determinants of the frequency and amplitude of growth hormone $(\mathrm{GH})$ secretory bursts and the half-life of endogenous GH in healthy men. Journal of Clinical Endocrinology and Metabolism 199173 1081-1088. (doi:10.1210/jcem-73-5-1081)

33 Scacchi M, Pincelli AI \& Cavagnini F. Growth hormone in obesity. International Journal of Obesity and Related Metabolic Disorders 1999 23 260-271. (doi:10.1038/sj.ijo.0800807)

34 Ranke MB, Lindberg A, Chatelain P, Wilton P, Price DA, Albertsson-Wikland K \& KIGS International Board. The potential of prediction models based on data from KIGS as tools to measure responsiveness to growth hormone. Pharmacia International Growth Database. Hormone Research 200155 (Suppl 2) 44-48. (doi:10.1159/000063474)

35 Blethen SL, Baptista J, Kuntze J, Foley T, LaFranchi S \& Johanson AJ. Adult height in growth hormone (GH)-deficient children treated with biosynthetic GH. The Genentech Growth Study Group. Journal of Clinical Endocrinology and Metabolism 1997 82 418-420. (doi:10.1210/jc.82.2.418)

36 Molitch ME, Clemmons DR, Malozowski S, Merriam GR, Shalet SM, Vance ML \& Stephens PA. Evaluation and treatment of adult growth hormone deficiency: an Endocrine Society Clinical Practice Guideline. Journal of Clinical Endocrinology and Metabolism 200691 1621-1634. (doi:10.1210/jc.2005-2227)

37 Biller BM, Samuels MH, Zagar A, Cook DM, Arafah BM, Bonert V, Stavrou S, Kleinberg DL, Chipman JJ \& Hartman ML. Sensitivity and specificity of six tests for the diagnosis of adult $\mathrm{GH}$ deficiency. Journal of Clinical Endocrinology and Metabolism 2002 87 2067-2079. (doi:10.1210/jc.87.5.2067)

38 Toogood AA, Jones J, O'Neill PA, Thorner MO \& Shalet SM. The diagnosis of severe growth hormone deficiency in elderly patients with hypothalamic-pituitary disease. Clinical Endocrinology 1998 48 569-576. (doi:10.1046/j.1365-2265.1998.00440.x)

39 Toogood AA \& Shalet SM. Growth hormone replacement therapy in the elderly with hypothalamic-pituitary disease: a dose-finding study. Journal of Clinical Endocrinology and Metabolism $1999 \mathbf{8 4}$ 131-136. (doi:10.1210/jc.84.1.131)

40 Franco C, Johansson G, Bengtsson BA \& Svensson J. Baseline characteristics and effects of growth hormone therapy over 2 years in younger and elderly adults with adult onset GH deficiency. Journal of Clinical Endocrinology and Metabolism 2006 11 4408-4414. (doi:10.1210/jc.2006-0887)

41 Monson JP, Abs R, Bengtsson BA, Bennmarker H, FeldtRasmussen U, Hernberg-Stâhl E, Thorén M, Westberg B, Wilton $\mathrm{P} \&$ Wüster C. Growth hormone deficiency and replacement in elderly hypopituitary adults. Clinical Endocrinology 200053 281-289. (doi:10.1046/j.1365-2265.2000.01104.x)

42 Corneli G, Di Somma C, Baldelli R, Rovere S, Gasco V, Croce CG, Grottoli S, Maccario M, Colao A, Lombardi G et al. The cut-off limits of the $\mathrm{GH}$ response to GH-releasing hormone-arginine test related to body mass index. European Journal of Endocrinology 2005 153 257-264. (doi:10.1530/eje.1.01967)

43 Dimke H, Flyvbjerg A \& Frische S. Acute and chronic effects of growth hormone on renal regulation of electrolyte and water homeostasis. Growth Hormone E IGF Research 200717 353-368. (doi:10.1016/j.ghir.2007.04.008)

44 Murray RD, Howell SJ, Lissett CA \& Shalet SM. Pre-treatment IGF-I level is the major determinant of $\mathrm{GH}$ dosage in adult $\mathrm{GH}$ deficiency. Clinical Endocrinology $2000 \mathbf{5 2} 537-542$. (doi:10.1046/j.13652265.2000.00971.x)

45 Trainer PJ, Barth J, Sturgeon C \& Wieringaon G. Consensus statement on the standardisation of GH assays. European Journal of Endocrinology 2006155 1-2. (doi:10.1530/eje.1.02186)

Received 9 May 2012

Revised version received 5 February 2013

Accepted 5 February 2013 